$\left.\begin{array}{c}\text { Sournals } \\ \text { ONTERNATIONAL JOURNAL OF } \\ \text { ORGANIZATIONAL LEADERSHIP }\end{array}\right) \begin{gathered}\text { INDUSTRIAL } \\ \text { MANAGEMENT } \\ \text { INSTITUTE }\end{gathered}$

\title{
Non-verbal communication barriers when dealing with Saudi sellers
}

\author{
Yosra Missaoui \\ Qassim University, College of Business and Economics, Business Administration Department, Kingdom of \\ Saudi Arabia
}

\begin{abstract}
Keywords:

Non-verbal

Communication, Saudi Sellers, Appearance, Body Language, Trainings

Correspondence:

yosrauniversity@gmail.com

Communication has a major impact on how customers perceive sellers and their organizations. Especially, the non-verbal communication such as body language, appearance, facial expressions, gestures, proximity, posture, eye contact that can influence positively or negatively the first impression of customers and their experiences in stores. Salespeople in many countries, especially the developing ones, are just telling about their companies' products because they are unaware of the real role of sellers and the importance of non-verbal communication. In Saudi Arabia, the seller profession has been exclusively for foreign labor until 2006. It is very recently that Saudi workforce enters to the retailing sector as sellers. The non-verbal communication of those sellers has never been evaluated from consumer's point of view. Therefore, the aim of this paper is to explore the non-verbal communication barriers that customers are facing when dealing with Saudi sellers. After discussing the nonverbal communication skills that sellers must have in the light of the previous academic research and the depth interviews with seven focus groups of Saudi customers, this study found that the Saudi customers were not totally satisfied with the current non-verbal communication skills of Saudi sellers. Therefore, it is strongly recommended to develop the non-verbal communication skills of Saudi sellers by intensive trainings, to distinguish more the appearance of their sellers, especially the female ones, to focus on the time of intervention as well as the proximity to customers.
\end{abstract}

(C)AIMI Journals

\section{Introduction}

When dealing with customers, effective seller's communication is extremely important to satisfy, attract, and retain clients. To gain a reputation for professional sales force, spoken communication is not enough. The non-verbal communication such as body language, 
appearance, facial expressions, gestures, proximity, posture, and eye contact are significant aspects of seller-customer's communication and can influence positively or negatively the first impression of customers and their store's experiences. During the last few decades, the study and the theory of non-verbal communication have become a popular interest in human and social sciences but still scarce in Marketing. The supremacy of non-verbal communication was approved by Albert Mehrabian (1969) in one of the most famous studies on non-verbal communication which found that 55 per cent of any message is transferred through non-verbal elements (facial expressions, gestures, posture, etc.), 38 per cent through the voice, and only 7 per cent through words.

The non-verbal communication is also recognized as affecting the persuasiveness of the message but has not been studied enough in the personal selling context (Williams \& Spiro, 1985). Few marketing research have investigated the seller's communication and fewer focused on sellers' non-verbal communication and its impact on customer impression. The majority of studies related to sales force have investigated the relation between buyer and seller in different perspectives. Some of these studies have studied the personal characteristics of the salesperson (Greenberg, 1964), others examined the factors influencing salesperson's performance. In addition, most conceptualizations of the buyer-seller interaction process examined the communication between the seller and the buyer in a general manner (Williams \& Spiro, 1985). Other empirical researches recognized that there is a widespread confusion between seller and teller due to the ignorance of the real role of seller who solves problems more than giving information.

In 2006, the Saudi government has taken a number of promising legislative steps named Saudization to encourage employment of Saudi nationals in the private sector that was largely dominated by expatriate workers. Consequently, the Saudi work force enters to the retailing sector as sellers. Despite the importance of sellers' non-verbal communication to satisfy customers in retailing sector, the investigation of Saudi sellers' non-verbal communication has never been inspected by academics and researchers. Thus, this study aims to explore the non-verbal communication barriers that customers are confronting when dealing with Saudi sellers and to give recommendations.

\section{The Importance of Communication in Selling}

According to Weitz (1978), the personal selling is the most important element in marketing communications to most business concerns. It's usually the only personal contact with customers by which the organizations convey and customize their messages according to customers' needs and wants. This personal communication can influence how that customer feels about the product, the manufacturer, the retailer, and the salesperson. In addition, it would offer manufacturers the opportunity to create a distinct competitive advantage (Dwyer, Schurr, \& Oh, 1987).

In retailing, professional sales force focus on communication to attract, convince, and influence the customers. According to Williams and Spiro (1985), the retail salesperson's most basic activity during the exchange is communication. Hence, successful selling depends on successful interpersonal communication. 
As such, to manage successfully a customer transaction, sellers need to have solid communication skills, active listening, good appearance, responsiveness, attentiveness, and friendliness. In essence, selling is communicating and telling is not enough to convince customers. The seller must gain prospect's conviction, be proactive and close sales which require non-verbal communication skills in addition to verbal communication and active listening skills.

Saxe and Weitz (1982) indicated that sellers must have two key skills including the ability to help and the ability to relate to others . Moreover, Damperat and Jolibert (2009) proposed that a good seller must be able to show cooperation and to create cordial interactions with the buyer. Others authors, highlighted others determinants to performant sellers, especially high energy level, self-confidence, hunger for money, well-established habits of industry, and the ability to see obstacles as challenges. In spite of its importance, the empirical researches investigating the customer-seller communication and its influences on personal selling were too scarce. Marketing researches has also emphasized mass communication rather than interpersonal communication (Capon, Hulbert, and Holbrook, 1976). Moreover, their research effort in advertising exceeds clearly those in personnal selling. They further explained this lack of research on selling by the complexity of interpersonal communication.

Most of the empirical research focused on the use of evidence in persuasive communication (McCroskey, 1969) and the oral communication and sales effectiveness (Pace, 1962). Others investigated the content of communication and distinguished types of bargaining behavior in retail transactions and studied its influences on the likelihood of purchase (Pennington, 1968). Nevertheless, the study of non-verbal communication in the personal selling context has remained neglected in marketing.

\section{The Non-verbal Communication in the Personal Selling}

Non-verbal communication is defined as communication without the use of words (Adejimola, 2008). It is defined also as behaviors, excluding the words themselves that could function as messages in a given speech community (Rubio Sanchez, Pico, \& Lucette, 2010). It's the behavior and elements of speech aside from the words themselves that transmit meaning. It includes pitch, speed, tone and volume of voice, gestures and facial expressions, body posture, stance and proximity, eye movements and contact, and dress and appearance. Miller and Steinberg (1975) indicated that people who understand communications know that non-verbal behavior is at least as important as the words people are mouthing. Fromkin and Rodman (1983) indicated that more than 90 per cent of the communication process is nonverbal. In addition, research related to salespeople emphasizes that 60 to 70 percent of all interpersonal communication is conveyed by non-verbal messages (Wood, 2004).

Despite the importance of non-verbal communication, the study of non-verbal communication in the personal selling context has remained neglected in marketing. Little research has investigated it in marketing and fewer have related it to personal selling. In his pioneer study, Pace (1962) investigated the oral communication attributes which differentiated between the more effective and the less effective sales representatives. The results of his empirical research applied in door-to-door salespeople, shows that the nonverbal communication such as use of voice, eye contact and body movement as 
communication skills aren't related to effectiveness in direct selling. However, the research suggests that the overall impression of communication skills and the use of language are a reliable criterion for differentiating superior from inferior sales people.

Conversely, Capon, Hulbert, and Holbrook (1976) emphasized, for the first time, the role played by non verbal communication in personal selling labeling them as non-verbal signs. Inspired by research outside marketing, they present a 12-celled matrix of interpersonal communications in which the majority of cell are non verbal signs and only one cell occupied by verbal communication. Those non-verbal signs including body movement, facial expressions, voice set, clothing and physical features, posture and distance, touching behavior, tactile and olfactory and eye line (eye contact). The research of Capon, Hulbert, and Holbrook (1976) demonstrated the importance of non-verbal signs in interpersonal communication, and recommend future researches to focus on both verbal and non-verbal communication to better modeling the interaction between seller and buyer. Moreover, Gabbott and Hogg (2000) empirically investigated the impact of non-verbal communication on service evaluation using an experimental methodology based on video scenarios to demonstrate the effect of this type of communication on consumers. The findings offered evidence that the non-verbal communication in a service encounter intensely impacts on the customer's evaluation of the service event.

Also, Leigh and Summers (2002) examined the effects of sellers' non-verbal communication in industrial sales and evaluated its impact on buyers' impressions and sales presentation. Their empirical findings indicated that non-verbal cues such as eye gaze, speech hesitations, professional attire, inflluence potentially buyers'perception of the salesperson and sales presentation. However, gesturing and formal posture showed no effects. In addition, multiple marketing studies of NLP (Neurolinguistics programming) suggest that the buyers' impressions of salesperson are formed by perceptions of non-verbal signs (Puce et al., 2003). Furthermore, It has been shown that a proper use of non verbal techniques increase consumer trust (Leigh \& Summers, 2002; Wood, 2004).

\section{The Non-verbal Communication Skills that a Seller Must Have}

Gabbott and Hogg (2000) stated that without the correct body language or paralinguistic cues customers are either dissatisfied or fail to develop the empathy with the provider which leads to repurchase behaviour. The key word here is correct. What is the correct non-verbal communication that a seller must have ?

Unfortunately, research has not proven the list of best non-verbal communication skills that a seller must have but the good news is that some researchers have recommanded and discussed the importance of some non-verbal behaviours and their effect on the customer. It was also recognized, that it's better to employ a combination of non-verbal signs, rather than just one, such as mainting eye contact or erect posture (Peterson, 2005). For example, Orthmann (1992) as a consultant and training professional specializing in sales and effective customer service, recommended a good appaearance and self confidence for successful sales professionals. A well-dressed seller can attract and convince customers more than bad dressed sellers. Buyers looking for signs of expertise will visually examine salespeople for appropriate appearance (Wood, 2004). According to Rubio Sanchez, Pico, and Lucette 
(2010), the physical appearance of the salesperson is the non-verbal factor that most impacts first impressions. Wood (2004) has proved empirically that the presence of appropriate appearance positively influences the assessments of expertise and trustworthiness by customers. Furthermore, Adejimola (2008) indicated that a businessman is supposed to sit down or stand up confidently while delivering their messages and his posture should suggest that he is confident and active. Concerning gestures, no special list was suggested in literature. The gestures must accomplish the meanings and ensure active participation by complementing speech with sign, usually by hands, and movements.

The effect of smile was investigated by Wood ( 2004) and the research results supported that the presence of a smile will positively influence assessments of sellers candor and trustworthiness. The speaker's voice must be clear, audible, and intelligible (Adejimola, 2008). So, the seller must also alter his voice in order to reach meanings and varieties of speech or voice including pitch, rate, and volume. Moreover, the eye contact is extremely important especially in western context. One research provided evidence that sustained eye contact can convey cooperation (Kurzban, 2001). Some patricians and researchers in communication have evidences supporting the significance of eye contact as a mean of sustaining and connecting the interest and attention of the audience or business partners (Adejimola, 2008).

\section{Retailing Sellers in Saudi Arabia after Saudization}

In 1990, the Saudi government took the decision to reduce the unemployment rate among native people. Therefore, the kingdom introduced the Saudization program to replace foreign workers with the appropriate Saudi workers. It is very recently that Saudi work force enters to the retailing sector as sellers. In 2011 the Kingdom introduced the program called "Nitaqat" which aims to offer job opportunities to nationals and demands that private companies operating in the kingdom increase the numbers of nationals' workers (Saidi \& Missaoui, 2014). Thus, a number of promising legislative steps was taken by saudi government and consequently have increased the presence of saudi in many domains that they couldn't enter to it before such as retailing, service sector and industrial sector. The non-verbal communication of those sellers has never been inverstigated. Given the demonstrated importance of non-verbal communication in personal selling and the skills that sellers must have, this present sudy aims to explore the non-verbal communication barriers that customers are confronting when interacting with Saudi sellers and to give suitable recommendations.

\section{Method}

This research was exploratory and it was based on qualitative data collection method using 7 focus groups. Each group contained 8 respondents who shared common interests. Also those respondents had different genders, educational levels, ages, positions and marital status. The focus groups' discussions were based on the structured interview with a high moderator involvement (Morgan, 1997). 


\section{Results}

Qualitative data analysis revealed six crucial themes across the seven focus groups. Themes showed that the most important non-verbal communication barriers of Saudi Sellers. Also those themes concentrated on the customers' impressions when interacting with Saudi sellers.

The first theme was the seller's posture. Many participants reported dissatisfaction with the poor posture of several Saudi sellers. We must notice also that the interviewees differentiate between male and female posture and also must notice that sellers in Jewelry and oriental perfumes stores seem to be more self-confident and motivated rather than other stores. Many respondents described negatively the female sellers' posture and express negative feelings about it. Regarding the posture, participants usually criticized that female sellers tend generally to sit down in the chair or in the ground while talking with customers or they stand up but without reflecting self confidence and dynamicity. According to many respondents, the postures of male sellers are better than female sellers. Moreover, some respondents compare saudi sellers to foreign ones and talk about lazy postures or postures wich reflect the lack of motivation and energy at many stores.

The second theme was the appearance and the clothing style. Expressing their satisfaction in general with saudi sellers' appearance, the majority of respondents acclaimed the clothing style of saudi sellers, the physical features, and the cleanlines. They affirmed that they were in general well-dressed and could attract and convince customers. However, when talking about female sellers'appearance, respondent stressed the difficulty to differentiate between female sellers from others women in the store. This confusion was due to the standardization of women wearing in Saudi Arabia which was related to the Saudi culture (Saudi women must wear Black Abaya and Black Nikab in the public places). Many resondents criticized this appearance and confirm that it inhibit them to talk with sellers.

One participant noted that when he entered in the stores, he was afraid it might be the wrong person and might offend him. The problem was that sellers wear like all other women including black abaya and black nikab without any distinction and this made them feel shy. Many respondants acclaimed also the Saudi national dress that sellers wear in some stores (jewerly, oriental perfumes, and dates stores) but prefer the uniform dress like tie combination or suit in stores where they bought modern articles (sports, cars, clothes, make up, and high tech products). The suit or the tie combination was perceived by the majority of respondant as a more professional dress. One of the interviewees raised an important point. He prefered to see sellers wearing the saudi dress in many stores, especially traditional stores like Incense stores, and dates stores. These traditional dresses reflected Saudi identity which was related to the type of store and she could trust the seller; however, he prefered the uniform dress in other stores including three-piece suit or tie combination. This interviewee prefered this dress in high tech and cars stores and believed that the uniform worn matches those type of store in other words a professional one.

The third theme was sellers' facial expressions. Participants discussed also different emotions when talking about sellers' facial expressions. They generally cannot describe exactly these but recognize that they differs from one to another and they cannot say that there is a problem in salesman's facial expression. The majority of the male participants acclaimed salesman's facial expression and describe them as smiling. Discussing how they 
felt about this posture some respondents explain that this position reveals that sellers arenot motivated or interested to serve them, and they are not qualified enough to deal with customers. One respondent explained that when he entered in a clothes store he didnot find femnale sellers easily, he looked for them and found them while sitting down in a corner. He stated that whenever he went shopping, he saw the females sellers that were lazy and nonmotivated. It made him nervous and he finally left the store. Another respondent discussed another experience. He stated that he did not notice any problem in male sellers faces in general and seemed to be happy with seller's facial signs.

One participant explained that fortunately he always noticed male sellers smiling at stores when they welcomed and when he was discussing with them. He felt that they were happy to serve him, and most of them talked and encouraged him to ask them more questions and they communicated easily with him. On the other hand, for some female repondents, the smile of salesman is required but must be formal, by formal they means strict and proper, if not they will feel shy and unconfortable and can leave the store. We must notice that in Saudi culture it's prohibited for male to smile at a non-Mahram (marriageable) woman or to look in her eyes . One respondent explained more those issues. He staed that she lived where the sellers were smiling to her and looking into her eyes. She felt like it was a probal temptation that made her feel unconfortable and she left the store. However, many respondents stated that they cannot see the facial expressions of female sellers because they wear in general Niqab which is a cloth that covers the face as a part of sartorial hijab. Respondents explained that the niqab do not represent a problem for them to communicate with female sellers because they were used to this but many female respondents prefered to deal with uncovered faces especially in cosmetics stores. One respondent talked about her experience which she could not distinguish facial expressions of female sellers because she wore niqab in general. The respondent did not know if she was happy or sad, smiling or not (laughing). She indicated that in many places she dealt with Saudi female sellers who do not cover their faces especially in Jedah and Ryadh in some luxury stores. Personally she prefered those uncovered faces in make up stores. In her perspective, sellers'faces can reflect their expertise and their professionalism in this domain. Another participant said that the niqab is not a problem for her and he could notice from the voice seller's or her eyes if he is interested to serve him or not. So, he can communicate easily with her even if she wear a niqab and he became accustomed to understand women behind it.

The fourth theme was seller's eye contact. In all focus groups, respondents accentued the importance of eye contact between them and the seller. For them it appeared affecting the persuasiveness of seller's message. One respondent reported that this eye contact is very important in the process of selling in a way that absorb the customers even if they know that the seller is lying or telling the truth. The results of this research proved that the eye contact problems differ according to the context and male-male encounter ,female-female, or femalemale encounter. For male-male encounter and female-female encounter, the majority of respondents criticize some eye contact signs that inhibit them to talk with sellers. The frequent problems cited by respondents is that Saudi sellers and especially female ones focus frequently their eyes on their mobile phone or the products and not on the customer. This behaviour made the customers feel angry and not satisfied. 
One respondent thought that the sellers sometimes avoid eye contact and look at the item that they sell or their mobile phone that gives him the impression that they are not interested and consequently he did not ask their help. For female-male encounter, another problem was emerged wich can be a barrier when dealing with salesmen. Many female respondents confirmed that they avoid to look at the salesmen and they prefered that sellers look at anything else. The direct eye contact between male and female (marriageable) can be perceived in Saudi culture as a lack of respect or temptation and it's consequently perceived negatively.

One female participant stated this subjet it's too rare that Saudi sellers look directly at our eyes and even if they looked at her eyes, she would feel shy to ask him anything and it disturbed her. Another respondent said that in dealing with men she prefered to avoid eye contact generally. If there was eye contact, she prefered to fixe her eyes to another thing includig ground and product. The female customers often prefer to deal with female sellers' because of their shyness.

The fifth theme was sellers' voice. For the majority of respondents, there is no voices' problem , their voices in general are clear and audible. One respondant said that the voice of sellers is clear in general and he did not remember having a problem with them. However, voice barrier emerged in some focus groups. Some female respondants discussed problems they had when they dialogued with some female sellers. Further, many participants said that those sellers talked with either a loud voice or inaudible voice. The voice volume can sometimes influence negatively the perceptions of sellers and make the communication bad and without interactivity. As one respondent said female sellers sometimes talk with an inaudible voice so that she asks them to repeat the answer another time or she tries to find the information or the item by herself. Another participant stated that sometimes some female sellers talk with unclear voices which inhibit her to ask them again.

The sixth theme was the proximity of customers. The closeness to customers was a nonverbal communication barrier discussed in many focus groups. Many respondents described it as a big communication barrier which made them feeling stressed. Discussing this communication barrier, respondent talked about feelings of embarrassment when she interact with some Saudi sellers. The closeness is embarassing, sometimes sellers stay too near to her and ask her many questions about how they can help her that really disturb her. Another respondant talked about an opposite experience. This respondent stated that she had not problem with salesmen because the salesmen keep distance with their female customers and she prefered formel distances between male sellers and herself.

The seventh theme was sellers' tardiness. Many respondents accentuated the frequent tardiness of sellers to response to their demands. Respondents criticized the loose of time when dealing with Saudi sellers both when purchasing and returning product. One respondent reported that Saudi sellers do not react quickly, walk slowly, and loose the time. Therefore, he sometimes tries to ask an expatriate seller in order to he will help him fastly. Another respondent explicated furiously that he went to a high-tech store and asked for a laptop. The seller disappeared suddenly when he went to search the item and he spent much time. So he left the store and he got angry. This reflects a bad idea about Saudi sellers' professionalim. On the other hand some participants expressed their satisfaction with the sellers' time of 
intervention. One of those participants stated that he really enjoyed his experience with Saudi sellers especially in dates store because seller welcomed him friendly and helped him to find the suitable items. These sellers were professional and helpful.

\section{Discussion and Conclusion}

The results of this exploratory research highlighted the importance of non-verbal communication when dealing with sellers. The findings also suggested that the most important non-verbal communication barriers in Saudi retailing context are the sellers' posture, appearance, and clothing style especially for Saudi female sellers, sellers' facial expressions, eye contact, voice, proximity to customers, and their tardiness.

The research attested that many Saudi sellers needs to acquire more non-verbal communication skills to attract and retain customers. The study findings provided information about customers' perception of the Saudi sellers' non-verbal cues. The study findings indicated that customers are not totally satisfied with the current non-verbal communication skills of Saudi sellers. The generalizability of the results may be limited because our sample was not representative to all Saudi customers. One potential limitation of this study was the small size of sample which could not representitive for larger population.

Spoken communication is not enough to satisfy customers. The non-verbal communication skills are a real tool that sellers can use to influence positively the first impression of customers and their experiences in the store. Nevertheless, this exploratory study revealed that non-verbal communication could be a threat in the personal selling if sellers were unaware of its importance and were not trained enough to use the non-verbal communication skills.

Our research aimed to explore the non-verbal communication barriers that customers are facing when dealing with Saudi sellers. Results showed that some barriers and recommendations were given to Saudi managers to improve the interaction between sellers and prospects. However, this work would be completed by others researches which investigating the non-verbal communication skills in personal selling in different cultures and using quantitative methods. Finally, this work could increase the sellers' communication and the customers' satisfaction in Saudi stores.

Talking is not enough to attract customers. In fact, the buyer-seller interaction is not determined only by their talks, the non-verbal communication is probably more important to satisfy customers. Therefore, it is strongly recommended to develop the non-verbal communication skills of Saudi sellers by intensive trainings, to distinguish more the appearance of their sellers, especially the female ones, to focus on the time of intervention as well as the proximity to customers.

Many customers talked about the non-verbal communication obstacles that inhibited them when interacting with Saudi sellers. Sellers can convey many negatives silent messages inconsciently which disturb customers and make them feel unconfortable. In our context, the appearance of female sellers was emerged as an important communication barriers. Hence, this study recommanded managers of Saudi stores to make the appearance of the female sellers more professional and more distinguished. They could use for example a colored abaya, badges, or any symbols that designates that they were the sellers. For salesmen, this study recommanded to wear suit or tie combination because it was perceived by the majority 
of respondant as a more professional dress relatively to Saudi national dress (Egal, thobe, and shemagh) which is recommanded in some stores taht reflect the saudi culture like jewerly, oud, oriental perfumes, and dates stores. The findings of this study also submitted a problem in seller's posture. So, the research recommended that female sellers must avoid sitting down in the ground when they communicates with their customers. Sellers must stand up self-confidently while sending their messages.

Sellers must also focus on the distance between themselves and the prospects, and must be distant enough to make customers feels comfortable. Of course, there is not an exact distance recommended, but sellers must adapt the distance according to their customers' feedback.

It is also strongly recommended to develop the body language skills of Saudi sellers by intensive trainings. Those trainings will enable the Saudi sellers to enhance and to improve their communication with prospects. This study also recommended sellers to intervene in the right time to satisfy customers and to avoid tardiness when serving the customers or the prospects (selling or returning a product).

Given that direct eye contact between male-female is perceived negatively by female customers in Saudi culture, this study recommended that sellers must avoid direct eye contact with female sellers. The smile of salesman is required but must be formal, strict, and proper to let female customers feel confortable in the store. For male-male or female-female interactions, the study suggested that sellers must avoid to look at their mobile phone or at the product when dialoguing with prospects and must maintain eye contact with their customers. It's recommanded that future research described more exactly the impact of non-vebal communication on the customers' satisfaction and examined the non-verbal communication skills in personal selling field and in different cultures. It's also recommanded that researchers uses methods other than focus groups to gather data about non-verbal communication in personal selling .

\section{References}

Adejimola, A. S. (2008). Language, communication, and information flow in entrepreneurship. African Journal of Business Management, 2(11), 201-208.

Capon, N., Hulbert, J. M., \& Holbrook, M. (1976). Interpersonal communication in marketing: An overview. Journal of Marketing Research , 9(1), 27-34.

Damperat, M., \& Jolibert, A. (2009). A dialectical model of buyer-seller relationships. Journal of Business \& Industrial Marketing, 24, 207-217.

Dwyer, F., Schurr, P. H., \& Oh, S. (1987). Developing buyer-seller relationship. Journal of Marketing, 5(1), 11-27.

Farley, J. U., \& Swinth, R. L. (1967). Effects of choice and sales message on customer-salesman interaction. Journal of Applied Psychology, 51(2), 107-110.

Gabbott, M., \& Hogg, G.(2000). An empirical investigation of the impact of non-verbal communication on service evaluation. European Journal of Marketing, 34(3/4), 384-398.

Greenberg, H. , \& Amabile, D. (1996). The personality of a top salesperson (11 ${ }^{\text {th }}$ ed.). Journal of Agency Sales, 26(11), 4041.

Greenberg , H., \& Mayer, D. (1964). A new approach to the scientific selection of successful salesmen. Journal of Psychology, 57, 113-123.

Kurzban, R. (2001). The social psychologics of cooperation: Non-verbal communication in public goods game. Journal of Nonverbal Behavior, 25(4), 241-259.

Leigh, T. W., \& Summers, J. O. (2002). An initial evaluation of indutrial buyers' impressions of salespersons' nonverbal cues. The Journal of Personal Selling \& Sales Management, 22(1), 41-53.

McCroskey, J. C. (1969). A summary of experimental research in the effects of evidences in persuasive communication. The Quarterly Journal of speech , 55(2),169-176.

Mehrabian, A. (1969). Significance of posture and position in the communication, attitude, and status relationships. Psychological Bulletin, 71, 359-372. 
Miller, G. R., \& Steinberg, M. (1975). Between people: A new analysis of interpersonal communication. Chicago: Science Research Associates.

Morgan, D. L. (1997). Focus groups as qualitative research, planning, and research design for focus group. Sage Research Methods, 4, 32-46.

Orthmann, P. (1992). Eight ingredients of successful salespeople. The American Salesman, 37(4),16-25.

Pace, W. R. (1962). Oral communication and sales effectiveness. Journal of Applied Psychology, 44, 487-488.

Pennington, A. L.(1968). Customer-salesman bargaining behavior in retail transactions. Journal of Marketing Research, 5(8), 255-262.

Peterson, R. T. (2005). An examination of the relative effectiveness of training in nonverbal communication : Personal selling implications. Journal of Marketing Education, 27(2), 143-150.

Puce, A., Syngeniotis, A., Thompson, J. C., Abbott, D . F., Wheaton, K. J., \& Castiello, U. (2003). The human temporal lobe integrates facial form and motion: Evidence from MRI and ERP. Neuroimage, 19(3),861-869.

Rubio Sanchez, A., Pico, A., \& Lucette, B. C. (2010). Salespeople's communication competence: A study of the Mexican market. Journal of Business \& Economic Studies, 16(1), 1-19.

Saidi, H., \& Missaoui, Y. (2014) . Customers' evaluation of Saudi female as sellers. Proceedings of the Second International Conference on Advances in Economics, Management, and Social Study, USA.

Saxe, R., \& Weitz, B. A. (1982). The SOCO scale: A measure of the customer orientation of salespeople. Journal of Marketing Research, 19(3), 343-352.

Weitz, B. A. (1978). Relationship between salesperson performance and understanding of customer decision making. Journal of Marketing Research, 15(4), 501-516.

Williams, K. C., \& Spiro, R. L. (1985). Communication style in the salesperson-customer dyad. Journal of Marketing Research, 22(4),434-442.

Wood, J. A. (2004). Perceptual cues that influence buyer's assessments about the trustworthiness of sellers during initial sales exchange (Unpublished doctarial dissertation). Georgia State University, United States. 